Pesq. Vet. Bras. 26(1):21-25, jan./mar. 2006

\title{
Intoxicação espontânea por Baccharis coridifolia (Compositae) em ovinos ${ }^{1}$
}

\author{
Daniela B. Rozza ${ }^{2}$, Djeison L. Raymundo², André M.R. Corrêa ${ }^{2}$, Juliano Leal ${ }^{2}$, \\ Anderson L. Seitz ${ }^{2}$, David Driemeier ${ }^{2}$ e Edson M. Colodel ${ }^{3 *}$
}

\begin{abstract}
Rozza D.B., Raymundo D.L., Corrêa A.M.R., Seitz A.L., Driemeier D. \& Colodel E.M. 2006. [Spontaneous Baccharis coridifolia (Compositae) poisoning in sheep.] Intoxicação espontânea por Baccharis coridifolia (Compositae) em ovinos. Pesquisa Veterinária Brasileira 26(1):2125. Departamento de Patologia Clínica Veterinária, Faculdade de Veterinária, Universidade Federal do Rio Grande do Sul, Av. Bento Gonçalves 9090, Cx. Postal 15094, Porto Alegre, RS 91540-000, Brazil.E-mail: moleta@terra.com.br

An outbreak of Baccharis coridifolia (Compositae) poisoning in sheep is reported, which occurred in November 2004 in the county of Caxias do Sul, Rio Grande do Sul (RS), southern Brazil. From a herd of 212 sheep, coming from a Baccharis coridifolia free area, in the county of Jaguarão, RS, 35 sheep died until 5 days after the arrival in the new area where the plant was found with abundance. The clinical signs began 8 hours after introduction of the animals into the new pasture and included apathy, anorexia, abdominal retraction or mild distension, weakness of hind limbs, dry feces, sternal ou lateral decumbency, struggling movements, coma and death. Clinical evolution was from 5 to 48 hours. Other sheep that were already before on the pasture were not affected. Main necropsy findings were in the gastrointestinal tube, with wall and serosal oedema, mainly in the reticulo-ruminal fold and of the abomasum, reddening and detachment of the mucosa of forestomachs, and intense hemorrhage in the submucosa. Histopathological findings were degeneration and necrosis of the epithelium of the forestomachs with polymorphonuclear infiltration associated with bacterial colonies, congestion, hemorrhage and oedema, and lymphoid tissue necrosis.
\end{abstract}

INDEX TERMS: Poisonous plants, Baccharis coridifolia, Compositae, plant poisoning, diseases of sheep, pathology.

RESUMO.- Descreve-se uma mortalidade de ovinos associada à intoxicação espontânea por Baccharis coridifolia ("mio-mio"). A intoxicação ocorreu no município de Caxias do Sul, RS, em novembro de 2004. De um lote de 212 ovinos, provenientes de pastagens livres de $B$. coridifolia, no município de Jaguarão, RS, morreram 35 ovinos em até 5 dias após serem liberadas para o pasto onde mio-mio era encontrado em abundância, apesar de terem sido removidos deste pasto 1 dia e meio após sua introdução. Ovinos que anteriormente estavam na pro-

\footnotetext{
${ }^{1}$ Recebido em 31 de agosto de 2005.

Aceito para publicação em 24 de outubro de 2005.

2 Depto Patologia e Clínica Veterinária, Faculdade de Veterinária, Universidade Federal do Rio Grande do Sul (UFRGS), Cx. Postal 15094, Porto Alegre, RS 91540-000.

${ }^{3}$ Depto Clínica Médica Veterinária, Faculdade de Agronomia e Medicina Veterinária, Universidade Federal de Mato Grosso (UFMT), Cuiabá, MT 78068-000. *Autor para correspondência. E-mail: moleta@terra.com.br
}

priedade não foram afetados. 0 quadro clínico iniciou-se 8 horas após a introdução dos animais na nova pastagem e incluiu anorexia, depressão, retração abdominal ou leve timpanismo, incoor-denação de membros posteriores, fezes pastosas, corrimento nasal catarral, decúbito lateral com movimentos de pedalagem, coma e morte com evolução clínica entre 5 e 48 horas. Os principais achados de necropsia foram no trato digestivo com edema de serosa e da parede dos préestômagos principalmente na região retículo-ruminal e do abomaso, avermelhamento e desprendimento da mucosa ruminal e do retículo e intensa hemorragia na submucosa. No exame histológico havia degeneração e necrose do epitélio do pré-estômago, com infiltrado polimorfonuclear, congestão, hemorragia e edema, e necrose do tecido linfóide de linfonodos, baço e trato digestivo.

TERMOS DE INDEXAÇÃO: Plantas tóxicas, Baccharis coridifolia, Compositae, intoxicação por planta, ovinos, patologia. 


\section{INTRODUÇÃO}

Baccharis coridifolia DC. ${ }^{4}$, subarbusto da família Compositae e conhecido por "mio-mio", é uma das mais importantes e comuns plantas tóxicas no sul do Brasil (Barros 1991, Tokarnia et al. 2000, Méndez \& Riet-Correa 2001). B. coridifolia é encontrada no Rio Grande do Sul, Santa Catarina, Paraná, São Paulo, grandes áreas do Uruguai, norte da Argentina e Paraguai. A planta é até 10 vezes mais tóxica na floração que brotação, porém a maioria dos relatos de intoxicação ocorre de setembro a novembro durante o período de brotação (Barros 1998).

Intoxicação espontânea por $B$. coridifolia é frequiente em bovinos, mas rara em eqüinos e suínos (Barros 1991, Tokarnia et al. 2000, Méndez \& Riet-Correa 2001, Rissi et al. 2005). São incomuns os relatos de intoxicação natural por $B$. coridifolia em ovinos (Barros, 1991), porém, assim como coelhos, são frequentemente utilizados para determinar o quadro clínico e patológico (Döbereiner et al. 1976, Tokarnia \& Döbereiner 1976, Barros 1991, Rodrigues \& Tokarnia 1995). Ovinos são mais resistentes que bovinos, adoecendo após o consumo do dobro da quantidade de B. coridifolia (Tokarnia \& Döbereiner 1976). De modo geral, em bovinos, a morbidade está em torno de $20 \%$ e a mortalidade é próxima de 100\% (Barros 1991, Rissi et al. 2005). Casos de intoxicação ocorrem em animais oriundos de regiões onde a planta não vegeta após o transporte para áreas com B. coridifolia. O risco de intoxicação aumenta consideravelmente após o transporte, se os animais passam fome em viagens, quando ocorre superlotação e quando são colocados em pastos altamente infestados por B. coridifolia (Barros 1991, Tokarnia et al. 2000, Méndez \& Riet-Correa 2001, Rissi et al. 2005). A intoxicação por mio-mio causa quadro clínico essencialmente agudo. Nos casos fatais em bovinos e ovinos, os sinais clínicos iniciam-se, respectivamente, 5-29 horas e 3-23 horas após a ingestão da planta verde, e a morte ocorre 3-34 horas e 2-42 horas após o aparecimento dos sinais clínicos. Os principais achados de necropsia são congestão, hemorragia e edema das paredes dos pré-estômagos, abomaso e intestino. As lesões histológicas consistem em degeneração, necrose do epitélio da mucosa dos pré-estômagos e abomaso e do tecido linfóide principalmente em linfonodos, baço e placas linfóides digestivas (Méndez \& RietCorrea 2001).

$O$ presente trabalho descreve o surto de intoxicação por $B$. coridifolia em um lote de ovinos, ocorrido em novembro de 2004 após o transporte para o município de Caxias do Sul, RS, e a reprodução experimental da intoxicação em coelhos para auxiliar na caracterização do quadro clínico e patológico associado ao consumo desta planta.

\section{MATERIAL E MÉTODOS}

Dados epidemiológicos e clínicos foram obtidos com os responsáveis pelo manejo dos ovinos e pela equipe do Setor de Patologia Veterinária (SPV) da Universidade Federal do Rio Grande do Sul (UFRGS), durante

\footnotetext{
${ }^{4}$ Identificação botânica da planta, coletada na propriedade com mortalidade de ovinos em Caxias do Sul, RS, foi realizada pelo Prof. Nelson Ivo Matzenbacher, da Pontifícia Universidade Católica do Rio Grande do Sul, Faculdade de Biociências, Departamento de Biologia (Avenida Ipiranga, 6681, Prédio 12, Botânica-Partenon, Porto Alegre, RS 90619-900).
}

visita a propriedade. Foram realizados necropsias e exames histológicos em seis animais afetados. Durante a necropsia fragmentos de fígado, rim, coração, pulmão, linfonodos, intestino, rúmen, retículo, omaso, abomaso e encéfalo foram coletados, fixados em formalina $10 \%$, processados rotineiramente para a histopatologia (Prophet et al. 1992) e corados por hematoxilina e eosina (HE) (Allen 1992).

Amostras de Baccharis coridifolia (Fig.1) foram coletadas na área de pastoreio dos ovinos e encaminhadas para análise botânica. Folhas foram administradas por via oral, forçada, para 3 coelhos em doses únicas de $3 \mathrm{~g} / \mathrm{kg}$ para um e $7 \mathrm{~g} / \mathrm{kg}$ para outros dois. Os coelhos foram acompanhados clinicamente e necropsiados. Durante a necropsia, fragmentos de vísceras foram coletados e conservados em formol $10 \%$ tamponado e processados rotineiramente para exame histopatológico.

\section{RESULTADOS}

Em 14.11.04, no município de Jaguarão, RS, foi agrupado um lote de 212 ovinos da raça Texel e lle de France. Os animais foram embarcados em 15.11.04 (manhã) e após 12 horas de viagem desembarcaram na propriedade no município de Caxias do Sul, RS. Em 16.11.04 (manhã) foram soltos num piquete de pasto nativo. Neste mesmo dia a tarde um ovino apresentou sinais clínicos caracterizados por apatia, anorexia, incoordenação motora, corrimento nasal, diarréia, decúbito esternal, decúbito lateral e morte com evolução clínica de 4 horas. Em 17.11.04 (à tarde) notou-se quadro clínico similar em vários ovinos e o lote foi retirado do piquete. Em 18.11.04 outros ovinos demonstraram os mesmos sinais clínicos e morte (Fig.2) com evolução de até 48 horas. Em 19.11.04 em visita à propriedade constatamos quadro clínico caracterizado por anorexia, depressão (Fig.3), retração ou leve timpanismo abdominal e fezes pastosas. Os ovinos permaneciam em estação por longos períodos sem se movimentar alheios ao ambiente ou caminhavam lentamente com passos curtos, arrastando as pinças e tinham incoordenação principalmente de membros posteriores. Notavam-se também corrimento nasal catarral, sialorréia, ranger de dentes, desidratação com endoftalmia e perda da elasticidade da pele. Finalmente permaneciam em decúbito esternal com cabeça apoiada no chão, posteriormente em decúbito lateral por vezes com movimentos de pedalagem, ficavam em estado comatoso seguido de morte. Nos 6 ovinos necropsiados notaram-se principalmente lesões no trato gastrintestinal. No pré-estômago próximo à prega retículo-ruminal havia leve a acentuado edema da parede ruminal e no sulco rumino-reticular. O rúmen estava distendido por conteúdo aparentemente normal ou em alguns casos pastoso. Principalmente no saco dorsal do rúmen e no retículo havia atenuação de papilas e que às vezes estavam irregulares e finamente recobertas por fibrina (Fig.4). $O$ epitélio era facilmente destacável expondo a lâmina própria intensamente avermelhada. $\mathrm{O}$ abomaso estava difusamente avermelhado e em três ovinos a região fúndica estava irregularmente enegrecida. Os linfonodos mesentéricos estavam aumentados em volume e edematosos ao corte. Petéquias e equimoses foram vistas principalmente nas serosas abdominal, torácica e pericárdica. $\mathrm{O}$ fígado estava mais pálido e com evidenciação do padrão lobular em alguns ovinos ou intensamente congesto em outros. No exame histológico as alterações degenerativas e necróticas do epitélio 

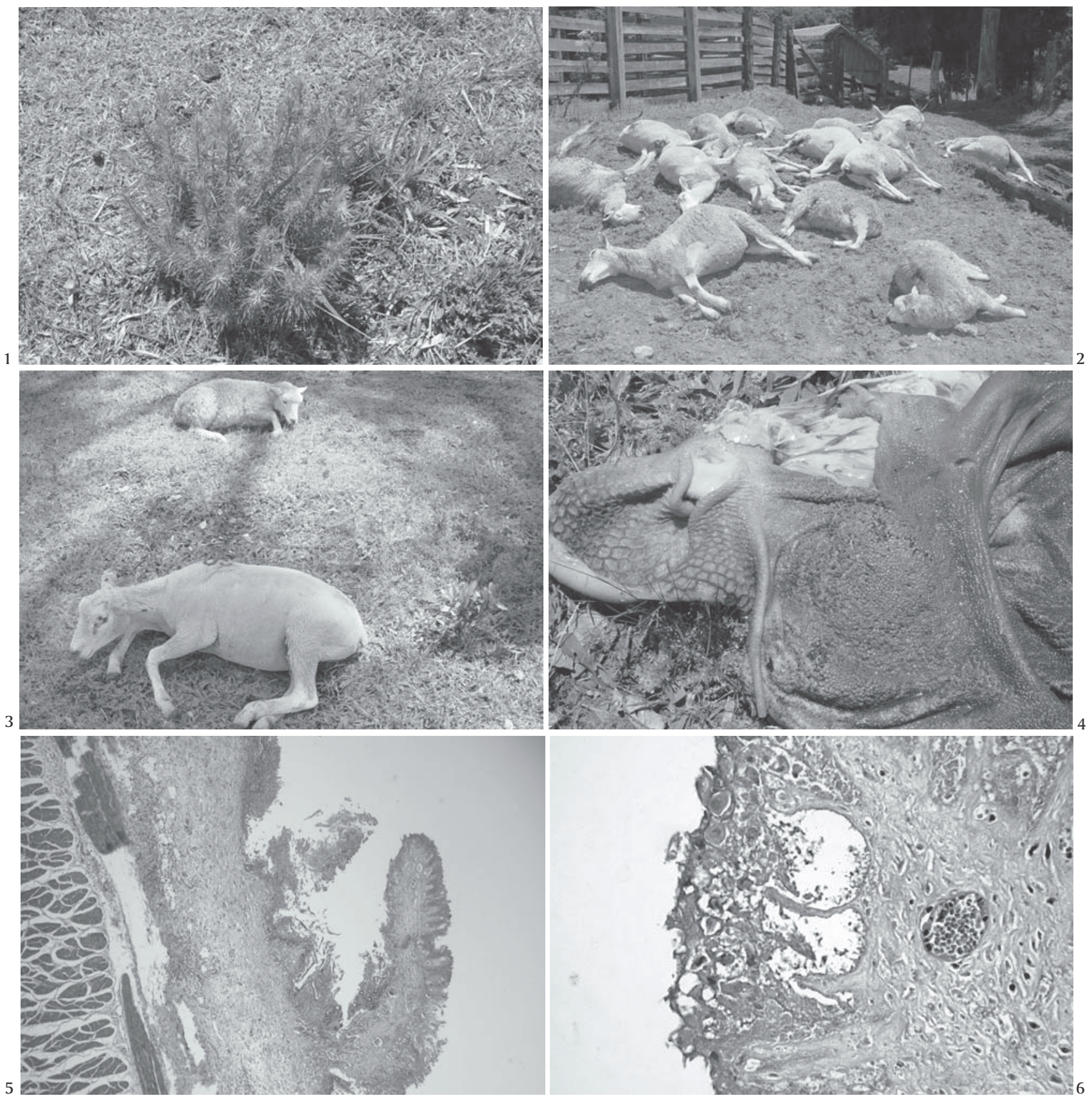

Fig.1. Brotação de Baccharis coridifolia em piquete de pastagem nativa na área onde ocorreu mortalidade de ovinos, em novembro de 2004. Caxias do Sul, RS.

Fig.3. Intoxicação espontânea por Baccharis coridifolia. Ovinos em decúbito esternal com acentuada depressão.

Fig.5. Necrose da mucosa do rúmen, na intoxicação natural por Baccharis coridifolia em ovinos. Notam-se vacuolização e dissociação celular na mucosa, e extensas áreas pavimentadas por bactérias basofílicas. HE, obj. 4 .

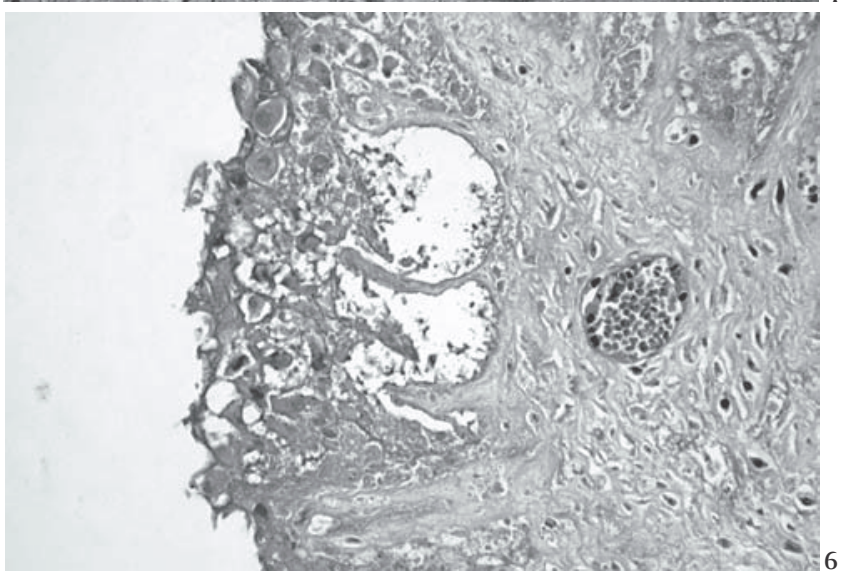

Fig.2. Mortalidade de ovinos associada ao consumo de Baccharis coridifolia em Caxias do Sul, RS.

Fig.4. Rúmen de ovino naturalmente intoxicado por Baccharis coridifolia. As papilas estão atenuadas, e há congestão e hemorragia na mucosa do rúmen e retículo.

Fig.6. Degeneração e necrose da mucosa do rúmen de ovinos naturalmente intoxicados por Baccharis coridifolia. Há tumefação e vacuolização citoplasmática, picnose e cariorrexia nuclear, e bactérias basofílicas invadindo a submucosa. HE, obj. 40. 
do trato digestivo (Fig.5) e de células linfóides foram os principais achados. Nas células do epitélio de revestimento do rúmen e retículo havia variáveis graus de degeneração hidrópica, tumefação e dissociação de células, eosinofilia do citoplasma com picnose e cariorrexia nuclear (Fig.6). Notava-se também edema intercelular, formação de vesículas principalmente próximas da junção basal algumas preenchidas com debris celulares, neutrófilos e bactérias. Havia também desaparecimento do epitélio de revestimento com exposição da lâmina própria associado com edema intercelular, restos celulares e densos agregados bacterianos, basofílicos, cocóides e/ou bacilares, além de congestão e hemorragia. No abomaso havia necrose coagulativa, multifocal da mucosa, com edema, congestão, hemorragia e presença de agregados bacterianos cocóides e/ou bacilares basofílicos. Necrose de células linfóides em diferentes graus de intensidade foi observada em linfonodos, no baço e no tecido linfóide digestivo envolvendo principalmente células centrais dos centros foliculares. No fígado havia tumefação difusa de hepatócitos, presença de corpúsculos acidófilos, necrose individual e aleatória de hepatócitos caracterizado por encarquilhamento celular, intensa eosinofilia citoplasmática, fragmentação nuclear, por vezes mais intensa em regiões centrolobulares, e infiltrado neutrofílico discreto aleatório. Em dois casos havia intensa tumefação e vacuolização do citoplasma de hepatócitos em regiões centrolobular. Na propriedade onde este lote foi alojado havia aproximadamente outros 200 ovinos dos quais nenhum adoeceu.

Após a administração de $B$. coridifolia para coelhos os que receberam $7 \mathrm{~g} / \mathrm{kg}$ apresentaram intensa depressão, anorexia, desidratação e diarréia líquida. Os sinais clínicos iniciaram aproximadamente 12 horas após a administração e tiveram curso de 3 horas. Na necropsia, o fígado estava amarelo-pálido e com o padrão lobular evidenciado. Principalmente a região fúndica do estômago estava vermelho-enegrecida, recoberta com fibrina. No ceco e cólon havia áreas multifocias, por vezes extensa com coloração vermelho-enegrecida, recobertas com muco e fibrina. A extremidade de algumas pregas cecais, principalmente próximo à válvula íleo-cecal, estavam intensamente avermelhadas, levemente e irregularmente atenuadas. Histologicamente estas áreas correspondiam a focos de degeneração e necrose no epitélio de revestimento além de variáveis graus de edema, congestão e hemorragia. $O$ coelho que recebeu $3 \mathrm{~g} / \mathrm{kg}$ de $B$. coridifolia não apresentou sinais clínicos.

\section{DISCUSSÃO}

O diagnóstico de intoxicação por Baccharis coridifolia nesse surto de mortalidade de ovinos foi baseado nos achados epidemiológicos, clínicos e patológicos. Evidências adicionais foram obtidas com a reprodução do quadro clínico e patológico em coelhos após a administração da planta coletada na área em que os ovinos desenvolveram quadro clínico.

Como descrito na intoxicação por $B$. coridifolia por Rodrigues \& Tokarnia (1995), Barros (1998) e Risse et al. (2005), acreditamos que fatores como a ausência de $B$. coridifolia na área de origem dos ovinos, o transporte, o período de fome entre o agrupamento do lote e a liberação dos ovinos no piquete infestado pela planta, que tinha sinais de consumo, contribuíram para ocorrência da intoxicação por $B$. coridifolia neste lote de ovinos. Estes fatores são reforçados pela observação dos ovinos que já estavam na propriedade e não adoeceram, pois possivelmente já tinham um prévio conhecimento da planta.

Os achados clínicos deste surto são consistentes com os descritos em casos experimentais de intoxicação por B. coridifolia em ovinos (Tokarnia \& Döbereiner 1976) e bovinos (Tokarnia \& Döbereiner 1975, Varaschin et al. 1998, Rissi et al. 2005) e similares aos descritos em ovinos experimentalmente intoxicados por Baccharis megapotamica var. megapotamica e var. weirii (Armién et al. 1993). A morbidade neste surto foi de $16,5 \%$ e todos os ovinos que manifestaram os sinais clínicos morreram. Aproximadamente 8 horas após a introdução dos ovinos no piquete se notou o primeiro animal doente, mas a maior parte dos que adoeceram, desenvolveram quadro clínico após o segundo dia de pastoreio. Até 5 dias após a introdução dos ovinos ocorreram novos casos clínicos, apesar do lote de ovinos ter sido removido deste pasto 1 dia e meio após sua introdução. A evolução clínica variou de 5 horas até 48 horas. Os principais sinais clínicos foram anorexia, severa depressão, leve timpanismo, alteração de consistência das fezes, instabilidade principalmente de membros posteriores, decúbito e morte. Fezes líquidas, frequentemente descrita em bovinos por vezes associada com prognóstico mais favorável (Tokarnia \& Döbereiner 1975, Varaschin et al. 1998), não foi observada neste surto.

Para o diagnóstico diferencial da intoxicação por B. coridifolia a intoxicação por B. megapotamica deve ser levada em conta. Em bovinos descreve-se que necrose de coagulação e lise de hepatócitos poderiam auxiliar na diferenciação (Tokarnia et al. 2000). Esta lesão não foi descrita na intoxicação experimental por B. megapotamica em ovinos (Armién et al. 1993) e não foi observada nesse surto de mortalidade de ovinos. Para essa conclusão são necessárias criteriosas observações epidemiológicas sobre o habitat da planta, pois B. megapotamica ocorre em áreas úmidas e $B$. coridifolia e encontrado em áreas secas. Enquanto $B$. coridifolia é ingerido por animais que desconhecem a planta, especialmente após o transporte $B$. megapotamica pode ser ingerido em épocas de carência de pastagem quando os animais entram em áreas úmidas infestadas pela planta.

A intoxicação por mio-mio em animais de interesse pecuário é comum e bem conhecida, principalmente nos Estados do Sul do Brasil, porém não há relatos da intoxicação por esta planta na Região Serrana do Estado do Rio Grande do Sul incluindo o município de Caxias do Sul. O consumo de B. coridifolia deve ser considerado em casos de mortes de bovinos e ovinos nessa região.

\section{REFERÊNCIAS}

Allen T.C. 1992. Hematoxylin and Eosin, p.53-58. In: Prophet E.B., Mills B., Arrington J.B. \& Sobin L.H. (ed.) Laboratory Methods in Histotechnology. Armed Forces Institute of Pathology, Washington, DC. 279p.

Armién A.G., Peixoto P.V. \& Tokarnia C.H. 1993. Intoxicação experimental por Baccharis megapotamica var. megapotamica e var. weirii (Compositae) em ovinos. Pesq. Vet. Bras. 13(1/2):5-20.

Barros C.S.L. 1991. Intoxicação por Baccharis coridifolia, p.159-169. In: Riet-Correa F., Méndez M.C. \& Schild A.L. (ed.) Intoxicação por Plantas e Micotoxicoses em Animais Domésticos. Editora Hemisfério Sul, Pelotas. 
Barros C.S.L. 1998. Livestock poisoning by Baccharis coridifolia, p.569 572. In: Garland T. \& Barr A.C. (ed.) Toxic Plants and Other Natural Toxicants. $\mathrm{CAB}$ International, Wallingford. 576p.

Döbereiner J., Rezende A.M.L. \& Tokarnia C.H. 1976. Intoxicação experimental por Baccharis coridifolia em coelhos. Pesq. Agropec. Bras. 11:27-35

Méndez M.C. \& Riet-Correa F. 2001. Intoxicações por Plantas e Micotoxinas, p.219-299. In: Riet-Correa F., Schild A.L., Méndez M.C. \& Lemos R.A.A. (ed.) Doenças de Ruminantes e Eqüinos. Vol. 2. Editora Varela, São Paulo.

Prophet E.B., Mills B., Arrington J.B. \& Sobin L.H. 1992. Laboratory Methods in Histotechnology. Armed Forces Institute of Pathology, Washington, DC. 279 p.

Rissi D.R., Rech R.R., Fighera R.A., Cagnini D.Q., Kommers G.D. \& Barros C.S.L. 2005. Intoxicação espontânea por Baccharis coridifolia em bovinos. Pesq. Vet. Bras. 25(2):111-114
Rodrigues R.L. \& Tokarnia C.H. 1995. Fatores que influenciam a toxidez de Baccharis coridifolia (Compositae): um estudo experimental em coelhos. Pesq. Vet. Bras. 18(2/3):51-69.

Tokarnia C.H. \& Döbereiner J. 1975. Intoxicação experimental em bovinos por “mio-mio", Baccharis coridifolia. Pesq. Agropec. Bras. 10:79-97.

Tokarnia C.H. \& Döbereiner J. 1976. Intoxicação experimental em ovinos por "mio-mio", Baccharis coridifolia. Pesq. Agropec. Bras. 11:19-26.

Tokarnia C.H., Peixoto P.V., Gava A. \& Barros C.S.L. 1992. Intoxicação experimental por Baccharis megapotamica var. megapotamica e var. weirii (Compositae) em bovinos.Pesq. Vet. Bras. 12(1/2):19-31.

Tokarnia C.H., Döbereiner J. \& Peixoto P.V. 2000. Plantas Tóxicas do Brasil. Editora Helianthus, Rio de Janeiro. 310p.

Varaschin M.S., Barros C.S.L. \& Jarvis B.B. 1998. Intoxicação experimental por Baccharis coridifolia (Compositae) em bovinos. Pesq. Vet. Bras. 18(2):69-75. 